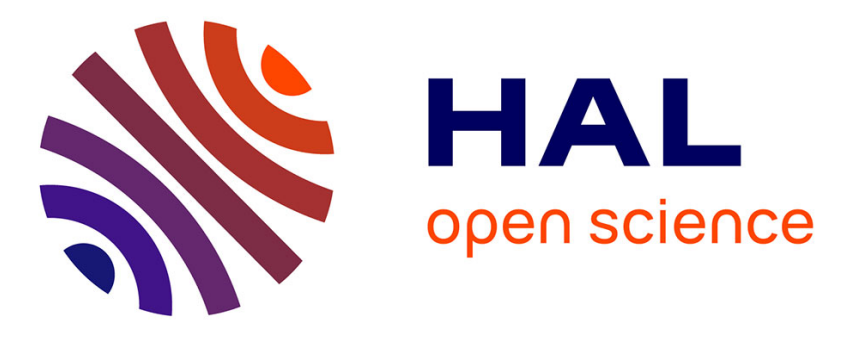

\title{
Keratosis Follicularis Spinulosa Decalvans is caused by mutations in MBTPS2
}

\author{
Emmelien Aten, Lisa C Brasz, Dorothea Bornholdt, Ingeborg B Hooijkaas, \\ Mary Porteous, Virginia P Sybert, Maarten H Vermeer, Rolf H.A.M. Vossen, \\ Michiel J.R. van Der Wielen, Egbert Bakker, et al.
}

\section{To cite this version:}

Emmelien Aten, Lisa C Brasz, Dorothea Bornholdt, Ingeborg B Hooijkaas, Mary Porteous, et al.. Keratosis Follicularis Spinulosa Decalvans is caused by mutations in MBTPS2. Human Mutation, 2010, 31 (10), pp.1125. 10.1002/humu.21335 . hal-00574002

\section{HAL Id: hal-00574002 https://hal.science/hal-00574002}

Submitted on 7 Mar 2011

HAL is a multi-disciplinary open access archive for the deposit and dissemination of scientific research documents, whether they are published or not. The documents may come from teaching and research institutions in France or abroad, or from public or private research centers.
L'archive ouverte pluridisciplinaire HAL, est destinée au dépôt et à la diffusion de documents scientifiques de niveau recherche, publiés ou non, émanant des établissements d'enseignement et de recherche français ou étrangers, des laboratoires publics ou privés. 
Human Mutation

WILEY

\section{Keratosis Follicularis Spinulosa Decalvans is caused by mutations in MBTPS2}

\begin{tabular}{|c|c|}
\hline Journal: & Human Mutation \\
\hline Manuscript ID: & humu-2010-0227.R1 \\
\hline Wiley - Manuscript type: & Rapid Communication \\
\hline $\begin{array}{r}\text { Date Submitted by the } \\
\text { Author: }\end{array}$ & 16-Jul-2010 \\
\hline Complete List of Authors: & $\begin{array}{l}\text { Aten, Emmelien; Leiden University Medical Center, Human \& } \\
\text { Clinical Genetics } \\
\text { Brasz, Lisa; Leiden University Medical Center, Human \& Clinical } \\
\text { Genetics } \\
\text { Bornholdt, Dorothea; Philipps University Marburg, Human Genetics } \\
\text { Hooijkaas, Ingeborg; Leiden University Medical Center, Human \& } \\
\text { Clinical Genetics } \\
\text { Porteous, Mary; West General Hospital, Clinical Genetics } \\
\text { Sybert, Virginia; University of Washington, Medicine } \\
\text { Vermeer, Maarten; Leiden University Medical Center, Dermatology } \\
\text { Vossen, Rolf; Leiden University Medical Center, Human \& Clinical } \\
\text { Genetics } \\
\text { van der Wielen, Michiel; Leiden University Medical Center, Human \& } \\
\text { Clinical Genetics } \\
\text { Bakker, Egbert; Leiden University Medical Center, Human \& Clinical } \\
\text { Genetics } \\
\text { Breuning, Martijn; Leiden University Medical Center, Human \& } \\
\text { Clinical Genetics } \\
\text { Grzeschik, Karl-Heinz; Philipps University Marburg, Human Genetics } \\
\text { Oosterwijk, Jan; University Medical Center Groningen, Clinical } \\
\text { Genetics } \\
\text { den Dunnen, Johan; Leiden University Medical Center, Human \& } \\
\text { Clinical Genetics }\end{array}$ \\
\hline Key Words: & $\begin{array}{l}\text { Keratosis Follicularis Spinulosa Decalvans, MBTPS2, IFAP, } \\
\text { Ichthyosis Follicularis }\end{array}$ \\
\hline
\end{tabular}

\section{SCHOLARONE ${ }^{\text {M }}$ \\ Manuscripts}




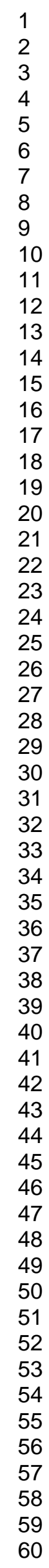

John Wiley \& Sons, Inc. 


\title{
Keratosis Follicularis Spinulosa Decalvans is caused by mutations in MBTPS2
}

E. Aten ${ }^{1}$, L. Brasz ${ }^{1}$, D. Bornholdt ${ }^{2}$, I.B Hooijkaas ${ }^{1}$, M.E. Porteous ${ }^{3}$, V.P. Sybert ${ }^{4}$, M. Vermeer ${ }^{5}$, R.HA.M. Vossen ${ }^{1}$, M.J.R. van der Wielen ${ }^{1}$, E. Bakker ${ }^{1}$, M.H.Breuning ${ }^{1}$, K.H. Grzeschik ${ }^{2}$, J. C. Oosterwijk ${ }^{6}$, J.T. den Dunnen ${ }^{1}$

\footnotetext{
${ }^{1}$ Center of Human and Clinical Genetics, Leiden University Medical Center, Leiden, the Nederlands. ${ }^{2}$ Department of Human Genetics, Philipps-Universität, Marburg, Germany. ${ }^{3}$ Department of Clinical Genetics, West General Hospital, Edinburgh, United Kingdom. ${ }^{4}$ Department of Medicine, University of Washington and Department of Dermatology, Group Health Permanente. ${ }^{5}$ Department of Dermatology, Leiden University Medical Center, the Netherlands. ${ }^{6}$ Department of Clinical Genetics, University Medical Center Groningen, Groningen, the Netherlands.
}

\begin{abstract}
$\underline{\text { ABSTRACT }}$
Keratosis Follicularis Spinulosa Decalvans, (KFSD, OMIM 308800) is a rare genetic disorder characterized by development of hyperkeratotic follicular papules on the scalp followed by progressive alopecia of the scalp, eyelashes and eyebrows. Associated eye findings include photophobia in childhood and corneal dystrophy. Due to the genetic and clinical heterogeneity of similar disorders, a definitive diagnosis of KFSD is often challenging. Towards identification of the causative gene we re-analysed a large Dutch KFSD family. 1M SNP arrays redefined the locus to a $2.9 \mathrm{Mb}$ region at Xp22.12-Xp22.11. Screening of all 14 genes in the candidate region identified MBTPS2 as the candidate gene carrying a c.1523A $>\mathrm{G}$ (p.Asn508Ser) missense mutation. The variant was also identified in two unrelated X-linked KFSD families and cosegregated with KFSD in all fami-
\end{abstract}


1

2

3

4

5

6

7

8

9

10

11

12

13

14

15

16

17

18

19

20

21

22

23

24

25

26

27

28

29

30

31

32

33

34

35

36

37

38

39

40

41

42

43

44

45

46

47

48

49

50

51

52

53

54

55

56

57

58

59

60

lies. In symptomatic female carriers, skewed X-inactivation of the normal allele matched with increased severity of symptoms. MBTPS2 is required for cleavage of sterol regulatory element-binding proteins (SREBPs). In vitro functional expression studies of the c. $1523 \mathrm{~A}>\mathrm{G}$ mutation showed that sterol responsiveness was reduced by half. Other missense mutations in MBTPS2 have recently been identified in patients with IFAP syndrome. We postulate that both phenotypes are in the spectrum of one genetic disorder with a partially overlapping phenotype.

Key words: Keratosis Follicularis Spinulosa Decalvans, MBTPS2, IFAP, Ichthyosis Follicularis

John Wiley \& Sons, Inc. 


\section{INTRODUCTION}

Keratosis Follicularis Spinulosa Decalvans (KFSD, OMIM 308800) is a rare genetic disorder showing variable expression with women usually less severely affected than men. In 1926, Siemens was the first to describe KFSD in a large German family and several Dutch cases (Siemens HW, 1926). These Dutch cases belonged to a large family that was described by Lameris (Lameris, 1905) under the name 'Ichthyosis Follicularis'. In the two large pedigrees described by Lameris and Siemens (Lameris, 1905; Siemens HW, 1926), inheritance is clearly X-linked. However, generally, 50\% of carrier females show symptoms of KFSD, which made Siemens postulate that inheritance in KFSD was of the X-linked intermediate type. More X-linked pedigrees have been described (Porteous et al., 1998). However inheritance is not always clear and isolated cases and autosomal dominant inheritance (i.e. male-to male transmission) has been described as well (Baden and Byers, 1994; Castori et al., 2009; Kuokkanen, 1971; Oosterwijk et al., 1997). KFSD manifests in infancy or early childhood with thorny keratotic follicular papules, progressive alopecia of the scalp, eyelashes and mainly lateral parts of the eyebrows with variable degrees of inflammatory change. Ocular abnormalities such as photophobia in childhood, punctate defects of the cornea, corneal dystrophy and blepharitis are common findings. Hyperkeratosis of elbows, knees, palms and soles as well as nail dystrophy may occur (Oosterwijk et al., 1997; Rand and Baden, 1983; Siemens HW, 1926; van Osch et al., 1992)

Due to the clinical and genetic heterogeneity of KFSD, a definite diagnosis is often challenging. KFSD resembles other dermatological entities such as keratosis pilaris and ulerythema ophrygenes (OMIM 604093), keratitis ichthyosis deafness syndrome (KID OMIM \#148210), ichthyosis follicularis atrichia photophobia (IFAP OMIM 
\#308205), keratosis pilaris atrophicans and atrophoderma vermiculatum.(Oranje et al.,

1994). The question remains whether these syndromes are in actual fact variations of the same entity or truly independent disorders.

Using linkage analysis in the Dutch KFSD family, the locus was mapped to Xp21.2-22.2 (Oosterwijk et al., 1992b). Subsequently, the disease location was narrowed down to Xp22.13-p22.2 (Oosterwijk et al., 1995) and later refined to Xp22.13-p22.11 (Oosterwijk et al., 1997). This locus was confirmed in an X-linked family from the UK (Porteous et al., 1998), but lack of informative crossovers prevented detection of the KFSD gene. In 2002, spermidine/spermine N(1)-acetyltransferase (SSAT OMIM \#313020) was postulated as the causative gene for $\mathrm{KFSD}_{\mathbf{r}}$ (Gimelli et al., 2002) . However, the $S A T 1$ gene is not included in the Dutch KFSD interval.

Deleted: , on the basis of a case report duplication and a clinical phenotype of mental retardation and also dermatologic symptoms of KFSD

In order to identify the causative gene, we studied the large Dutch family and some other families with a clinical diagnosis of KFSD using new molecular tools. 1M SNP arrays were used to refine the locus and to exclude the involvement of large deletions and duplications. Subsequently, genes in the candidate gene interval were screened for possible pathogenic variants using High Resolution Melting curve Analysis (HRMA). Here, we show that KFSD patients carry mutations in the MBTPS2 gene and that this affects the normal function of the protein by lowering MBTPS2 activity. While this work was in progress, deficiencies in the MBTPS2 gene were shown to also cause IFAP syndrome (Oeffner et al., 2009). Together this sheds new light on the genetic and clinical heterogeneity of these related disorders. 


\section{MATERIALS AND METHODS}

\section{Study subjects}

An extended multigenerational Dutch pedigree with 21 affected males, 15 unaffected males and 12 female carriers was available for molecular analysis (Figure 1a). Female carriers showed a variable phenotype ranging from severely affected to total absence of KFSD symptoms (van Osch et al., 1992).

Other families and cases with a clinical diagnosis of KFSD were available for MBTPS2 analysis. Two families showed a clear X-linked mode of inheritance, confirmed by microsatellite marker analysis: a family from the USA as seen by one of us (unpublished data V.P.Sybert ), and a family from the UK that was published previously (Herd and Benton, 1996; Porteous et al., 1998). The American family (Figure 1b) consisted of five affected males, five unaffected males and three carrier females. Four individuals were available for DNA analysis. Seven family members from the UK family (pedigree available in Herd and Benton et al, 1996) (Herd and Benton, 1996) were available for DNA analysis. Clinical features and MBTPS2 genotypes are summarized in Table 1.

\section{DNA and RNA analysis}

DNA was extracted from whole blood following standard protocols. Total RNA was extracted from whole blood lymphocytes and from cultured fibroblasts using RNA| bee ${ }^{\mathrm{Tm}}$ (Bioconnect). cDNA was made using 1ug of total RNA according to standard protocols. Fibroblasts were cultured in DMEM (Gibco) with $10 \%$ FCS, $1 \%$ Penicilin + 
1

2

3

4

5

6

7

8

9

10

Streptomycin, $1 \%$ glutamine and $1 \%$ glucose at $37^{\circ} \mathrm{C}$ and $5 \% \mathrm{CO}_{2}$. Cells were harvested at $90 \%$ confluency prior to RNA isolation.

\section{Array platforms}

For SNP typing and CNV analysis, the Illumina Human1M BeadChip (Illumina Inc., San Diego, CA, USA) was used and a total of $750 \mathrm{ng}$ DNA was processed according to the manufacturer's instructions. SNP copy number (log R ratio) and B-allele frequency were assessed using the software programs BeadStudio version 3.2 (Illumina).

\section{High Resolution Melting Curve Analysis}

High Resolution Melting curve Analysis (HRMA) was used as a pre-mutation screening in the Dutch KFSD family. Primers were designed to cover all exons and intron/exon boundaries of the 14 candidate genes (Fig 2) using Lightscanner primer design (Idaho). Known SNPs were avoided as much as possible. Sequences are available on request. Fragments were amplified using a touchdown PCR $\left(65^{0}-59^{0}\right)$ directly followed by melting (LightCycler 480 Roche). To detect possible heteroduplex formation, patient DNA was mixed with DNA from unaffected male individuals in a 1:1 ratio. Melting curves of mixed samples were compared to those of unmixed samples and healthy controls. Samples showing aberrant melting curves were selected for direct sequence analysis. 


\section{Sequence analysis}

PCR products were purified using spin columns according to the manufacturer's instructions (Qiagen, The Netherlands) and directly sequenced using Sanger sequencing (ABI 3730). High-throughput PCR products were purified using magnetic beads (Ampure) and prepared for sequencing with Sephadex plates (Edge Biosystems). Sequencing analysis was performed using the Mutation Surveyor program (SoftGenetics, USA). The human assembly (GRCh37/Hg 19) was used as a reference sequence. Nucleotide numbering follows HGVS recommendations and is based on a coding DNA reference sequence with nucleotide 1 corresponding to the A of the ATG translation initiation codon (www.hgvs.org/mutnomen). For MBTPS2 exon 11 all available subjects from the Dutch pedigree were sequenced to study the segregation of the MBTPS2 c. $1523 \mathrm{~A}>\mathrm{G}$ mutation in this family. Cases from two other X-linked KFSD families from the USA and UK were also tested for this variant. The remaining 6 families were screened for all exons of the MBTPS2 gene. 50 healthy unrelated controls were sequenced and data from pilot study 1 of the 1000 genome project (www.1000genomes.org, version October 2009) was used to study the variant frequency in the healthy population.

To confirm our findings on RNA level and to study possible differences in expression, MBTPS2 mutation screening was performed at both RNA and genomic DNA levels. Possible damaging effects of missense mutations were assessed by PolyPhen and SIFT software. A web based MBTPS2 gene variant database using the LOVD platform 
(Fokkema et al., 2005) was initiated to store and share all data collected (see

www.LOVD.n1/MBTPS2).

\section{$\mathrm{X}$-chromosome inactivation}

The methylation status of the X-chromosome was determined using the Androgen Receptor (AR) locus (Kubota et al., 1999). The maternal and paternal X chromosomes are distinguished by polymorphisms of a CAG repeat element in the AR gene while X-

| inactivation level is determined by the methylation of $\mathrm{CpG}$ dinucleotides in the $A R$ gene. Four carrier females and one affected male of the Dutch pedigree were genotyped for their CAG repeat length in the AR gene (Xq12) using blood derived DNA. The sequence of the forward primer with the fluorescent dye FAM was 5'-

ACCGAGGAGCTTTCCAGAAT-3'. The sequence of the reverse primer was 5'-

CTCATCCAGGACCAGGTAGC-3'. To determine the methylation status of the AR gene alleles in the carrier females, DNA was treated with bisulphite followed by a methylation specific PCR (according to the manufacturer's protocol EZ DNA methylation-Gold kit $^{\mathrm{Tm}}$, Zymo research). Methylation differences were estimated based on peak heights in the PCR fragment analysis (Genemarker V1.70, Softgenetics).

\section{Complementation assay}

Growth of stably transfected CHO-K1-M19 cells was measured in cholesterol rich medium compared to cholesterol deficient medium. CHO-K1-M19 cells (MBTPS2 deleted) were grown in a 1:1 mixture of Ham's F-12 medium and DMEM containing Glu- 
tamax (Invitrogen), nonessential amino acids, penicillin, streptomycin (Medium A), supplemented with $10 \%$ FCS and maintained at $37^{\circ} \mathrm{C}$ and $5 \% \mathrm{CO}_{2}$. Cells were stably transfected with 1.5 ug of a plasmid (pcDNA3.1 vector expressing a neomycin resistance gene, Invitrogen) expressing WT human MBTPS2 or the N508S mutant MBTPS2. Stable transfection of CHO-K1-M19 cells with WT human MBTPS2 restores the enzyme defect, thereby allowing growth in sterol deficient media. Cell growth of the N508S mutant transfected CHO-K1-M19 and WT transfected cells was measured in medium with- (Medium A with 5\% FCS, 5ug/ml water-soluble cholesterol, $1 \mathrm{mM}$ sodium mevalonate and $20 \mathrm{uM}$ sodium oleate) and without sterols (Medium A with 5\% lipoprotein deficient FCS). Growth of the stable transfected CHO-K1-M19 cells was measured after 6 days of culturing. Cells were harvested at day 6 and cells were counted in a hemocytometer. The complementation assay was performed as described by Oeffner et al (Oeffner et al., 2009).

\section{Luciferase Reporter Assays}

This assay, an indirect measure of the ability of MBTPS2 cDNAs to restore sterolregulated transcriptional activity in transfected M19 cells with a firefly pSRE-Luciferase reporter plasmid, was performed as described by Oeffner et al (Oeffner et al., 2009; Zelenski et al., 1999). In short, CHO-K1-M19 cells were transfected with expression plasmids without MBTPS2 cDNA insert, wild-type or mutant MBTPS2 and a reported plasmid ( $p S R E-G L 4.23)$ in which the luciferase reporter gene is under transcriptional control of the human LDL receptor promotor (Sterol Regulatory Element, SRE) and a Renilla luciferase plasmid ( $p R L-S V 40$ ) as a transfection control. Cells were cultured for

John Wiley \& Sons, Inc. 
1

2

3

4

5

6

7

8

9

10 16h in Medium A and then switched to medium B. Firefly- and Renilla-luciferase activity were measured in a luminometer Auto Lumat LB953 (Berthold Technologies).

\section{Immunohistochemistry}

Skin biopsies of four carrier females and two affected males were obtained and stored at $-80^{\circ} \mathrm{C}$. Cryosections were cut at $0,05 \mu \mathrm{m}$. Sections were fixed for $5^{\prime}$ in cold acetone and blocked for $20{ }^{\prime} 0,12 \% \mathrm{H}_{2} \mathrm{O}_{2}$ in demi water. After washing, sections were blocked in $1 \%$ NGS in PBS and incubated with primary antibody overnight. Rabbit aMBTPS2 (Cell Signaling) (1:200 dilution in 1\%NGS in PBS) and Mouse $\alpha$ Keratin 10 as a positive control (NeoMarkers Inc Fremont, California, USA.) (1:50 dilution in 1\% NGS

Deleted: in a Deleted: in a in $\mathrm{PBS}$ ) were used as primary antibodies. Secondary antibody (Invitrogen) incubation in a 1: 1000 dilution for 1 hour was followed by incubation with Streptavidine-HRP antibody (Southern Biotechnology Associates) for one hour (1:2000). DAP+ was used to develop staining and sections were counterstained using Haematoxylin. 


\section{RESULTS}

Descendants of an extended Dutch pedigree (Oosterwijk et al., 1992a; Oosterwijk et al., 1992b; Oosterwijk et al., 1995; Oosterwijk et al., 1997) were subject to clinical and molecular analysis. First, to map the locus more accurately we analysed several members of each family using 1M SNP arrays. Analysis included the critical recombinants VII-12 and VI-29 (Figure 1a Dutch Pedigree) which defined the borders of the KFSD locus.

Disease segregation fully matched with published linkage data (Oosterwijk et al., 1997). In addition we were able to redefine the region more precisely to a $\sim 2.9 \mathrm{Mb}$ region with the proximal breakpoint between chrX:19390769G $>\mathrm{C}$ and rs5955562 and the distal breakpoint between rs6528097 and rs4408025. Copy number variations ( $>5$ consecutive SNPs) were not detected in this region or in any other genomic region, thereby excluding deletions or duplications as a possible genetic cause.

This refined region in Xp22.12-Xp22.11 contains 14 genes (Figure 2). HighResolution Melting curve Analysis (HRMA) was used to screen these genes for sequence variants (Figure 2) in patients versus controls. Aberrant melt curves in one or more samples and thereby sequence variants were detected in 4 genes (Supp. Table S1). The variant in the MBTPS2 gene was considered as the most promising disease-causing variant since it occurred in all affected males and changes a highly conserved amino acid (p.Asn508Ser) (Figure 2).

Deleted: (FLJ14503, MAP3K15 MBTPS2, ZNF645) : NM_152780.2:c.545A $>$ G $(r s 34519770)$, NM_001001671.2:c.1533+19G $>$ C (rs56058646), NM_015884.2: c. $1523 \mathrm{~A}>\mathrm{G}$ and

NM_152577.2:c.498C $>$ A (rs5951426).

Deleted: 3

The c.1523A $>\mathrm{G}$ variant showed full co-segregation with the disease in the Dutch family (Figure 3a). We analysed the MBTPS2 gene in two other KFSD families with an established X-linked inheritance, an UK family reported by Porteous et al (Herd and Benton, 1996; Porteous et al., 1998) and a USA family ascertained and investigated by Sybert (personal communication, unpublished data). In both families exactly the same 
c.1523A $>$ G (p.Asn508Ser) variant was identified. The mutation was not detected by direct Sanger sequencing of 86 control chromosomes. Haplotype analysis around MBTPS2 made a close relationship between these families very unlikely, the maximum region of overlap being at most $50.1 \mathrm{~Kb}$ (Supp. Table S2).

Skin biopsies and whole blood samples were obtained from 7 individuals from the

Dutch family. RNA analysis showed the expected variant in the RNA (c.1523A>G).

Since the variant lies in the last exon we analysed a potential effect on RNA splicing using 3'RACE, but no effect could be detected. Carrier females showed variability in the expression of the mutated and the wild type allele (Figure $3 \mathrm{~b}$ ). To exclude RNA stability differences, the allelic expression was correlated to the level of $\mathrm{X}$-inactivation (Xi) using a methylation assay. Imbalances in allelic expression perfectly matched with skewed levels of X-inactivation and more interestingly with the clinical phenotype. This was most striking in a mother (VI-19) and her two daughters (VII-10 and VII-11). The mother preferentially expresses the mutant allele and has a moderate phenotype. One of her two daughters without any symptoms of KSFD only expresses the wild-type allele, while the second, mildly to moderately affected daughter expresses both the disease-and wild-type allele (Table 2).

Expression of MBTPS2 mRNA in fibroblasts was studied by qRT-PCR using RNA isolated from two male KFSD patients and five carrier females. MBTPS2 has two transcripts. The shorter transcript ranges from exon 1 up to exon 7, the full length transcript ranges from exon 1 up to exon 11. Using transcript specific primers, no significant differences in expression of the shorter or longer transcripts were found in fibroblast derived mRNA from carrier females (data not shown). Significantly higher expression of 
the full length MBTPS2 transcript was found in carrier females $(\mathrm{n}=3)$ compared to con-

trols $(\mathrm{n}=5)$, while there are no significant differences in expression in affected males

Deleted: supplementary data

$(\mathrm{n}=2)$ compared to controls $(\mathrm{n}=3)(\underline{\mathrm{Supp}}$, Figure $\mathrm{S} 1)$.

The amino acid Asn508 is located in an evolutionary conserved hydrophobic

transmembrane region of the protein. Online prediction tools (Polyphen and Sift) indicate that the Asn508Ser amino acid substitution, which shows the same polarity, is benign. To test the effect on protein function, in particular the effect on sterol responsiveness, we used the in vitro tests developed by Oeffner et al. (Oeffner et al., 2009). Wild-type MBTPS2 stably transfected into CHO-M19 cells were compared to Asn508Ser MBTPS2 transfected cells and examined using complementation analysis. The number of cells transfected with the mutant MBTPS2 able to grow in absence of sterols was lower compared to cells transfected with wild-type MBTPS2 (Figure 4a). The luciferase reporter assay showed a clear reduction in sterol responsiveness in Asn508Ser MBTPS2 transfected CHO-M19 cells, as compared to wild-type MBTPS2 transfected cells (Figure 4b). The effects on the normal function of MBTPS2 were in the same range as those found in IFAP syndrome cases (Oeffner et al., 2009).

$\underline{\text { To study whether a functional effect of the c. } 1523 \mathrm{~A}>\mathrm{G} \text { MBTPS2 mutation could }}$ be detected; we have made an in vivo plasma lipid profile of an affected male. No abnormal lipid levels as compared to standard reference levels were detected (Cholesterol: 4.9 refs: $3.9-7.3 \mathrm{mmol} / \mathrm{L}$, Triglycerides:1.7 refs: $0.8-2.3 \mathrm{mmol} / \mathrm{L}$, HDL: 0.95 refs: $0.9-1.41$ mmol/L, LDL: 3.18 refs: $<3.0 \mathrm{mmol} / \mathrm{L}$ ). Ultracentrifuge lipid profiling did not show abnormalities in VLDL-triglyceride value $(0.95 \mathrm{mmol} / \mathrm{L})$ or VLDL cholesterol/ratio

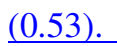


S3) was performed for four carrier females and two affected males and three controls.

The results did not show any clear differences between patients and controls and indicate normal expression MBTPS2 levels for affected males, carrier females and controls. 


\section{DISCUSSION}

Based on the criteria for designating a mutation as phenotype-modifying (Cotton and Scriver, 1998), the results from the current study provide enough evidence to establish that the $c .1523 \mathrm{~A}>\mathrm{G}$ variant in MBTPS2 cause X-linked KFSD. Screening of all genes in the candidate disease gene region, identified only one potential disease-causing variant, a missense change c.1523A $>\mathrm{G}$ (p.Asn508Ser) in MBTPS2. The variant was identified in two other unrelated X-linked KFSD families and perfectly co-segregates with the disease in all three families. The c. $1523 \mathrm{~A}>\mathrm{G}$ variant was not detected by direct Sanger sequencing of 86 control chromosomes, it is not listed in the results of pilot study 1 of the 1000 genomes (www.1000genomes.org, checked October 2009) nor has it been reported in dbSNP. To facilitate future studies, in particular clinical diagnostic studies of skin $\underline{\text { defects, we established a gene variant database for MBTPS2 }}$ (http://www.LOVD.nl/MBTPS2) following HGVS reccomendations (www.HGVS.org). The database currently contains 30 different variants of which 9 have been associated with pathogenicity (including KFSD and IFAP syndrome). The c.1523A $>\mathrm{G}$ variant affects a well conserved amino acid in a highly conserved gene. Differences in allelic expression of MBTPS2 could be correlated to the clinical phenotype of carrier females. In Deleted: has not been reported before (see http://www.LOVD.nl/MBTPS2) and affects a well conserved amino acid in a highly conserved gene.

fibroblasts and skin biopsies, qRT-PCR data and immunohistochemical staining of MBTPS2 show normal expression levels in affected males. Western blot analysis and immunofluorescence experiments in fibroblasts (Supp. Figure S4) are in agreement with Deleted: data not shown these findings and show normal expression levels and protein localization. Functional analysis of the mutant gene however, showed significant reduction in sterol responsiveness, indicating loss of proteolytic activity of the MBTPS2 protein. 
1

2

3

4

5

6

7

8

9

10
In total, we have studied nine families with a clinical diagnosis of KFSD and identified the same mutation in the MBTPS 2 gene in 26 cases (three families). In six small families, lacking a clear X-linked mode of inheritance, the molecular basis of the disease is as yet unidentified. Although detailed clinical and histological data of these cases/families are not available, it is possible that they were misdiagnosed due to the similarity of KFSD to several other dermatological entities. Another possibility is that KFSD is a locus heterogeneous disorder and that there are other causative gene mutations. A critical review of these and other mutation negative cases may lead to other diagnosis or other loci. MBTPS2 mutations have recently been identified in IFAP patients (Oeffner et al., 2009). In IFAP syndrome, the clinical severity varies to a large degree, while in KFSD most affected individuals have a relatively mild phenotype. This could be due to a genotype-phenotype effect, depending on the position of the mutation in MBTPS2. Elucidation of the MBTPS2 crystallography and its biochemical function is necessary to make clear correlations.

Until now, the diagnosis of KFSD has been based on clinical findings and its differential diagnosis has long been under debate (Oranje et al., 1994). Siemens described clinical findings of non-inflammatory, flesh-colored spinous 'thorns' leaving follicular scars where the skin subsequently becomes atrophic. It affects hair growth on the scalp, lateral eyebrows and eyelashes accompanied with the onset of alopecia during early adolescence. Patients can also have punctate defects on the cornea, palmoplantar hyperkeratosis with normal nails. IFAP (Macleod and Collins, 1908) was described coincidently also as 'Ichthyosis Follicularis' with noninflammatory spiny excrescences, hyperkeratosis and noncicatricial alopecia and photophobia. IFAP syndrome (MIM 308205) shares sev-
Deleted: While this work was ongoing, Oeffner et al (Oeffner et al., 2009) identified MBTPS 2 mutations in IFAP patients. Together with our findings of a MBTPS2 mutation in KFSD patients it is still under debate whether these clinical disorders are simply variations of the same entity or different diseases.
Deleted: Although these features had also been found in other conditions, Siemens believed this to be a distinct disorder and named it keratosis follicularis spinulosa decalvans (cum ophiasi)(Siemens HW, 1926). IFAP

Deleted: was first described by Mcleod 
eral features with KFSD, but differentiation is believed to be made on a congenital nonscarring nature of the alopecia. Until now, the small number of published cases, the phenotypic variability in both IFAP and KFSD with clinical overlap and the absence of a molecular cause made it impossible to determine if these syndromes were actual variations of the same entity or truly independent disorders. Much confusion has been generated in literature because of erroneous reporting of cases with lack of clinical details and reports of autosomal modes of inheritance. For instance the case report in which KFSD-

like signs were present in a boy due to an unbalanced X-chromosomal duplication led to Deleted: with multiple congenital the notion that SATI (Gimelli et al., 2002) was the plausible gene for KFSD (SSAT OMIM \#313020). But putriscine levels and SSAT activity were normal in the Dutch KFSD family, which makes SSAT overexpression a very unlikely cause for isolated (i.e. nonsyndromic) KFSD.

The pathogenesis of KFSD is largely unknown. An epidermal defect is highly likely since cells from the skin, hair and the cornea are involved. The epidermis has a protective function as the outer layer of the skin. The cornification of the skin's surface is compensated for by renewal of the epidermis, controlled by proliferation and differentiation of keratinocytes. As they move towards the upper layers, the keratinocytes become flatter and produce a mixture of lipids, cholesterol, free saturated fatty acids and ceramides into the intercellular spaces and thereby contributes to making the epidermis an effective barrier. Decreased cholesterol content in the stratum corneum could be attributable to the barrier function abnormality (Elias et al., 2008; Williams and Elias, 1981). Several human genodermatoses have been described with mutations of genes involved in various aspects of lipid metabolism (Elias et al., 2008), such as Ichthyosis prematurity

John Wiley \& Sons, Inc. 
syndrome (Klar et al., 2009), lamellar ichthyosis (Lefevre et al., 2003), harlequin

ichthyosis (Kelsell et al., 2005), Conradi-Hünermann-Happle syndrome, (Braverman et

al., 1999), CHILD syndrome (Konig et al., 2000) and X-linked Ichthyosis (Basler et al., 1992), to which MBTPS2 is now added, causing both IFAP and KFSD.

MBTPS2 functions as a metalloprotease, required for cleavage of sterol regulatory

element-binding proteins (SREBPs). Within a feedback mechanism the active domain of

| SREBPs is cleaved by S2P and transported to the nucleus to function as a transcription

factor of several targets genes, amongst which the LDL receptor gene. For both men and

women, residual protease activity of MBTPS2 will most likely determine the severity of

disease. However, measurements of proteolytic activity of MBTPS2 are not straightfor-

ward. Changes in proteolytic activity may have their effect elsewhere in the sterol regu-

lated pathway which may result in general lipid abnormalities. Our study of serum lipids

in one KFSD patient does support this hypothesis but rigourous investigation in a case-

control study is needed given all the factors which affect this pathway.

When the $\mathrm{X}$-activation is skewed towards expression of the mutated allele, an $\mathrm{X}$ -

linked recessive disorder may affect female carriers, and the residual enzyme activity of

MBTPS2 determines their phenotype. Therefore, skewed X-inactivation has been postu-

lated as an explanation for heterogeneity in KFSD carrier females given the fact that the

number of symptomatic carrier females seems larger then expected on the basis of ran-

dom lyonisation. We have shown that differences in Xi-pattern expressions indeed may

be correlated to the severity of KFSD symptoms in females. It is remarkable that while in

some X-linked recessive diseases (Duchenne Muscular Dystrophy MIM \#310200, Red-

Green Colour blindness MIM + 303800/303900) females rarely show symptoms, in oth- 
ers, like KFSD and OTC (MIM \#311250), this is frequent. Interestingly, Siemens used

Deleted: Although the link to nonrandom $\mathrm{X}$-inactivation is evident one

wonders why in some disorders this seems to go to either extreme while in KFSD as the first disorder in which he recognised X-linked intermediate inheritance others it results in extraordinary variable expression. (Siemens HW, 1926). However, the distinction between different modes of X-linked inheritance is a mere quantative aspect of several underlying mechanisms, one of them being skewed Lyonisation. The standard concepts of dominance or recessiveness do often not apply to X-linked diseases (Dobyns et al., 2004) and KFSD should therefore also be simply described as X-linked inheritance.

\section{Conclusion}

This study supports a new approach towards patients who are referred to a medical clinic with KFSD or IFAP. First, critical assessment of all the symptoms together with a thorough family history is important for establishing a differential diagnosis. In patients that show the triad of follicular ichthyosis (follicular hyperkeratosis), total or subtotal atrichia of scalp, eyebrows or eyelashes and photophobia at a young age, IFAP/KFSD should be considered. When X-linked inheritance cannot be excluded, mutation analysis for MBTPS2 is warranted and will be crucial to confirm this diagnosis. To prevent more confusion in the nosology of this disorder, we propose a new name should be chosen for KFSD/IFAP syndrome and suggest this name will be used when a MBTPS2 mutation has been detected. If MBTPS2 mutation analysis is negative, the extension '-like syndrome' should be added. This new nomenclature should be introduced when DNA analysis has been performed in enough KFSD/IFAP and KFSD/IFAP-like families and all clinical features have been reviewed. 


\author{
Acknowledgements \\ We gratefully acknowledge all patients for their kind collaboration to publish clinical \\ data. We thank M. Pietila, Kuopio, Finland for putriscine levels and SSAT activity meas- \\ urements. B. Loeys is thanked for his cooperation in completing the genealogy records of \\ the Dutch family. Technicians from the Department of Cytogenetics and LDGA are \\ kindly thanked for technical assistance. We would like to thank Y. Ariyurek for assis- \\ tance with the 1M arrays and Dr. A.H.M Smelt for his help and expertise in lipid profil- \\ ing. Drs H. de Kort is thanked for her expertise in immunohistochemistry. Drs S. Com- \\ mandeur and Dr. R. van Doorn are kindly thanked for supplying the Mouse $\alpha$ Keratin 10 \\ antibody and useful suggestions. Dr. W.M.C van Roon-Mom, T. Messemaker, E. de \\ Meier, J. Celli and Y. Lai are acknowledged for all their help and support.
}


Reference List

Baden HP, Byers HR. 1994. Clinical findings, cutaneous pathology, and response to therapy in 21 patients with keratosis pilaris atrophicans. Arch Dermatol 130:469-475.

Basler E, Grompe M, Parenti G, Yates J, Ballabio A. 1992. Identification of point mutations in the steroid sulfatase gene of three patients with X-linked ichthyosis. Am J Hum Genet 50:483-491.

Braverman N, Lin P, Moebius FF, Obie C, Moser A, Glossmann H, Wilcox WR, Rimoin DL, Smith M, Kratz L, Kelley RI, Valle D. 1999. Mutations in the gene encoding 3 beta-hydroxysteroid-delta 8, delta 7-isomerase cause X-linked dominant Conradi-Hunermann syndrome. Nat Genet 22:291-294.

Castori M, Covaciu C, Paradisi M, Zambruno G. 2009. Clinical and genetic heterogeneity in keratosis follicularis spinulosa decalvans. Eur J Med Genet 52:53-58.

Cotton RG, Scriver CR. 1998. Proof of "disease causing" mutation. Hum Mutat 12:1-3.

Dobyns WB, Filauro A, Tomson BN, Chan AS, Ho AW, Ting NT, Oosterwijk JC, Ober C. 2004. Inheritance of most $\mathrm{X}$-linked traits is not dominant or recessive, just $\mathrm{X}$ linked. Am J Med Genet A 129A:136-143.

Elias PM, Williams ML, Holleran WM, Jiang YJ, Schmuth M. 2008. Pathogenesis of permeability barrier abnormalities in the ichthyoses: inherited disorders of lipid metabolism. J Lipid Res 49:697-714.

Fokkema IF, Den Dunnen JT, Taschner PE. 2005. LOVD: easy creation of a locusspecific sequence variation database using an "LSDB-in-a-box" approach. Hum Mutat 26:63-68.

Gimelli G, Giglio S, Zuffardi O, Alhonen L, Suppola S, Cusano R, Lo NC, Gatti R, Ravazzolo R, Seri M. 2002. Gene dosage of the spermidine/spermine N(1)acetyltransferase ( SSAT) gene with putrescine accumulation in a patient with a Xp21.1p22.12 duplication and keratosis follicularis spinulosa decalvans (KFSD). Hum Genet 111:235-241.

Herd RM, Benton EC. 1996. Keratosis follicularis spinulosa decalvans: report of a new pedigree. Br J Dermatol 134:138-142.

Kelsell DP, Norgett EE, Unsworth H, Teh MT, Cullup T, Mein CA, Dopping-Hepenstal PJ, Dale BA, Tadini G, Fleckman P, Stephens KG, Sybert VP, Mallory SB, North BV, Witt DR, Sprecher E, Taylor AE, Ilchyshyn A, Kennedy CT, Goodyear H, Moss C, Paige D, Harper JI, Young BD, Leigh IM, Eady RA, O'Toole EA. 2005. Mutations in ABCA12 underlie the severe congenital skin disease harlequin ichthyosis. Am J Hum Genet 76:794-803. 
Klar J, Schweiger M, Zimmerman R, Zechner R, Li H, Torma H, Vahlquist A, Bouadjar B, Dahl N, Fischer J. 2009. Mutations in the fatty acid transport protein 4 gene cause the ichthyosis prematurity syndrome. Am J Hum Genet 85:248-253.

Konig A, Happle R, Bornholdt D, Engel H, Grzeschik KH. 2000. Mutations in the NSDHL gene, encoding a 3beta-hydroxysteroid dehydrogenase, cause CHILD syndrome. Am J Med Genet 90:339-346.

Kubota T, Nonoyama S, Tonoki H, Masuno M, Imaizumi K, Kojima M, Wakui K, Shimadzu M, Fukushima Y. 1999. A new assay for the analysis of X-chromosome inactivation based on methylation-specific PCR. Hum Genet 104:49-55.

Kuokkanen K. 1971. Keratosis follicularis spinulosa decalvans in a family from northern Finland. Acta Derm Venereol 51:146-150.

Lameris. 1905. Ichthyosis Follicularis. Nederlands Tijdschrift Voor Geneeskunde 41:1524.

Lefevre C, Audebert S, Jobard F, Bouadjar B, Lakhdar H, Boughdene-Stambouli O, Blanchet-Bardon C, Heilig R, Foglio M, Weissenbach J, Lathrop M, Prud'homme JF, Fischer J. 2003. Mutations in the transporter ABCA12 are associated with lamellar ichthyosis type 2. Hum Mol Genet 12:2369-2378.

Macleod JM, Collins ET. 1908. Two Cases of Advanced "Keratosis follicularis," associated with Baldness. Proc R Soc Med 1:27-31.

Oeffner F, Fischer G, Happle R, Konig A, Betz RC, Bornholdt D, Neidel U, Boente MC, Redler S, Romero-Gomez J, Salhi A, Vera-Casano A, Weirich C, Grzeschik KH. 2009. IFAP syndrome is caused by deficiency in MBTPS2, an intramembrane zinc metalloprotease essential for cholesterol homeostasis and ER stress response. Am J Hum Genet 84:459-467.

Oosterwijk JC, Nelen M, van Zandvoort PM, van Osch LD, Oranje AP, Wittebol-Post D, van Oost BA. 1992a. Confirmation of X-linked inheritance and provisional mapping of the keratosis follicularis spinulosa decalvans gene on $\mathrm{Xp}$ in a large Dutch family. Ophthalmic Paediatr Genet 13:27-30.

Oosterwijk JC, Nelen M, van Zandvoort PM, van Osch LD, Oranje AP, Wittebol-Post D, van Oost BA. 1992b. Linkage analysis of keratosis follicularis spinulosa decalvans, and regional assignment to human chromosome Xp21.2-p22.2. Am J Hum Genet 50:801-807.

Oosterwijk JC, Richard G, van der Wielen MJ, van d, V, Harth W, Sandkuijl LA, Bakker E, van Ommen GJ. 1997. Molecular genetic analysis of two families with keratosis follicularis spinulosa decalvans: refinement of gene localization and evidence for genetic heterogeneity. Hum Genet 100:520-524. 
Oosterwijk JC, van der Wielen MJ, van d, V, Voorhoeve E, Bakker E. 1995. Refinement of the localisation of the $\mathrm{X}$ linked keratosis follicularis spinulosa decalvans (KFSD) gene in Xp22.13-p22.2. J Med Genet 32:736-739.

Oranje AP, van Osch LD, Oosterwijk JC. 1994. Keratosis pilaris atrophicans. One heterogeneous disease or a symptom in different clinical entities? Arch Dermatol 130:500-502.

Porteous ME, Strain L, Logie LJ, Herd RM, Benton EC. 1998. Keratosis follicularis spinulosa decalvans: confirmation of linkage to Xp22.13-p22.2. J Med Genet 35:336-337.

Rand R, Baden HP. 1983. Keratosis follicularis spinulosa decalvans. Report of two cases and literature review. Arch Dermatol 119:22-26.

Siemens HW. 1926. Keratosis Follicularis Spinulosa Decalvans. Arch Dermat Syphilil 151:384-387.

van Osch LD, Oranje AP, Keukens FM, Voorst Vader PC, Veldman E. 1992. Keratosis follicularis spinulosa decalvans: a family study of seven male cases and six female carriers. J Med Genet 29:36-40.

Williams ML, Elias PM. 1981. Stratum corneum lipids in disorders of cornification: increased cholesterol sulfate content of stratum corneum in recessive $\mathrm{x}$-linked ichthyosis. J Clin Invest 68:1404-1410.

Zelenski NG, Rawson RB, Brown MS, Goldstein JL. 1999. Membrane topology of S2P, a protein required for intramembranous cleavage of sterol regulatory elementbinding proteins. J Biol Chem 274:21973-21980. 
Figure 1a. Dutch KFSD pedigree with twenty-one affected males and twelve carrier females. The family shows a clear X-linked pattern of inheritance, as proven by microsatellite marker analysis. Key recombinants (VII:12 and VI:29) determine the KFSD locus.

Figure 1b. KFSD family from the USA with five affected males and three carrier females, suggestive of X-linked inheritance.

Figure 2. The KFSD locus. The KFSD linkage locus was redefined at Xp22.12-Xp22.11. High Resolution Melting curve Analysis (HRMA) identified MBTPS2 as a candidate gene in the Dutch KFSD family. The detected variant in MBTPS2 is indicated in red. Previously identified mutations in IFAP syndrome are indicated in black.

Figure $3, M B T P S 2$ mutation analysis in the Dutch KFSD family. a) Sanger sequencing of exon 11 in the $M \bar{B} T P S 2$ gene identified a c. $1523 \bar{A}>\mathrm{G}$ (p.Asn508Ser) in all affected males of the Dutch KFSD family, not present in WT controls. The variant co-segregates with the disease in this family; affected male (VI-20) c.1523A $>\mathrm{G}$, carrier female (VI-27) c.1523AG and unaffected male (VII-6) c.1523G. b) RNA analysis in fibroblasts in the Dutch KFSD family. cDNA sequencing in fibroblasts confirmed the presence of the c.1523A $>\mathrm{G}$ variant in an affected male. Carrier females (VI-19, VII-11, VI-27, and VII-10) showed variability in the expression of the mutated and the wild type allele.

| Figure 4 Complementation assay and luciferase reporter assay. Functional studies of the c. $1523 \mathrm{~A}>\mathrm{G}$ ( $\mathrm{p}$. A sn $508 \mathrm{Ser})$ variant using an in vitro assay testing sterol responsiveness. A. Complementation assay: Growth of stably transfected CHO-K1-M19 cells (lacking hamster MBTPS2) was measured in cholesterol rich medium (blue) and cholesterol deficient medium (red). The proportion of cells capable of growth is documented as framed photographs of the cultures and, graphically in bars by counts of growing stably transfected cells. Colours indicate absence (red) or presence (blue) of sterols. B. Luciferase reporter assay: luciferase activity functions as an indirect measure of the ability of MBTPS2 mutants to restore sterol-regulated transcriptional activity in transfected CHO-K1-M19 cells. Cells transfected with the $c .1523 \mathrm{~A}>\mathrm{G}$ (p.Asn508Ser) variant are less able to restore sterol-regulated transcription compared to wild type when transferred from a cholesterol rich (blue bars) to a cholesterol deficient medium (red bars).

Table 1. Clinical features and MBTPS2 genotypes of affected individuals and carrier females in 9 KFSD families. 
Table 2.X-inactivation patterns in the Dutch KFSD family. Levels of X-inactivation in carrier females were compared to the differences in $\mathrm{RN} A \mathrm{~A}$ expression in fibroblasts. $\mathrm{a}^{*}=$ less expression of the wild type allele compared to other carrier females. The clinical phenotype of carrier females matched with differences in Xinactivation.

Figure S1. MBTPS2 levels in KFSD males compared to control males

Figure S2. Skin biopsies stained with aMBTPS2 (brown) with (A) and without (B) Haematoxylin. 40x and 20x magnification. Epi=epidermis, $\mathrm{SC}=$ stratum corneum, $\mathrm{SG}=$ stratum granulosum, $\mathrm{SS}=$ stratum spinulosum, $\mathrm{SB}=$ stratum basale.

Figure S3: Skin biopsy stained with $\alpha$ Keratin-10 (A) and only counterstaining with Haematoxylin (B). 20x and 10x magnification. Keratin-10 is expressed in the epidermis, except the stratum basale.

Figure S4: Cellular localisation of MBTPS2 in fibroblasts. There is no difference between a control male (a) and a male KFSD patient VII-12 (b). MBTPS2 (green fluorescence) is found both in the cytoplasm and nucleus. Nuclei are stained in blue with DAPI. Red is a control staining of $\beta$-actin.

Table S1.Variants detected in the KFSD locus (Xp22.12-Xp22.11) using High Resolution Melting curve Analysis (HRMA).

Table S2. Haplotype comparison around MBTPS2. 
Figure 1a. Dutch KFSD pedigree with twenty-one affected males and twelve carrier females. The family shows a clear X-linked pattern of inheritance, as proven by mi-crosatellite marker analysis. Key recombinants (VII:12 and VI:29) determine the KFSD locus. $170 \times 127 \mathrm{~mm}(300 \times 300 \mathrm{DPI})$ 
Figure 1b. KFSD family from the USA with five affected males and three carrier females, suggestive of X-linked inheritance.

$170 \times 110 \mathrm{~mm}(300 \times 300 \mathrm{DPI})$ 
Table 1. Clinical features and MBTPS2 genotypes of affected individuals and carrier females in 9 KFSD families.

\begin{tabular}{|c|c|c|}
\hline Family/Proband & Clinical Features & $\begin{array}{l}\text { MBTPS2 Genotype affected } \\
\text { individuals }\end{array}$ \\
\hline 1 Dutch & van Osch et al., 1992 & $\begin{array}{l}\text { c. }[1523 \mathrm{~A}>\mathrm{G}]+[0] \text { in males } \\
\text { c. }[1524 \mathrm{~A}>\mathrm{G}]+[=] \text { in females }\end{array}$ \\
\hline $2 \mathrm{UK}$ & Herd and Benton et al., 1996 & $\begin{array}{l}\text { c. }[1523 \mathrm{~A}>\mathrm{G}]+[0] \text { in males } \\
\text { c. }[1524 \mathrm{~A}>\mathrm{G}]+[=] \text { in females }\end{array}$ \\
\hline 3 USA/ II: 1 & $\begin{array}{l}\text { dry bumpy skin, facial } \\
\text { erythema, lack of eyebrows, } \\
\text { absence body hair, } \\
\text { photophobia, cracked feet } \\
\text { with hyperkeratosis, } \\
\text { unspecified alopecia }\end{array}$ & c. $[1523 \mathrm{~A}>\mathrm{G}]+[0]$ \\
\hline 3 USA/III: 1 & $\begin{array}{l}\text { dry skin, slightly thinned } \\
\text { eyebrows with full } \\
\text { eyelashes. sparse body hair }\end{array}$ & c. $[1524 \mathrm{~A}>\mathrm{G}]+[=]$ \\
\hline 3 USA/IV:1 & $\begin{array}{l}\text { dry bumpy skin, lack of } \\
\text { eyebrows, intact eyelashes, } \\
\text { facial erythema, } \\
\text { hyperkeratotic heels, severe } \\
\text { photophobia, recurrent } \\
\text { episodes of blepharitis, no } \\
\text { hair loss on scalp, no } \\
\text { scarring. Normal tooth } \\
\text { development, Normal } \\
\text { fingernails and cuticles. }\end{array}$ & c. $[1523 \mathrm{~A}>\mathrm{G}]+[0]$ \\
\hline 3 USA/IV:2 & $\begin{array}{l}\text { dry bumpy skin, lack of } \\
\text { eyebrows, lack of lower } \\
\text { eyelashes, photophobia, } \\
\text { facial erythema. Normal } \\
\text { tooth development. }\end{array}$ & c. $[1523 \mathrm{~A}>\mathrm{G}]+[0]$ \\
\hline 4-9 miscellanies & $\begin{array}{l}\text { Diagnosed by clinician as } \\
\text { 'KFSD' }\end{array}$ & $\begin{array}{l}\text { c. }[=]+[0] \text { in males } \\
\text { c. }[=]+[=] \text { in females }\end{array}$ \\
\hline
\end{tabular}

All sequence information is based on GenBank reference sequence NM_015884.2.

Nucleotide numbering follows HGVS recommendations and is based on a coding DNA reference sequence with nucleotide 1 corresponding to the A of the ATG translation initiation codon (www.hgvs.org/mutnomen). c.[=] denotes a normal wild type sequence, c.[0] indicates that no paternal allele is present. 
Figure 2. The KFSD locus. The KFSD linkage locus was redefined at Xp22.12-Xp22.11. High Resolution Melting curve Analysis (HRMA) identified MBTPS2 as a candi-date gene in the Dutch KFSD family. The detected variant in MBTPS2 is indi-cated in red. Previously identified mutations in IFAP syndrome are indicated in black. $175 \times 161 \mathrm{~mm}(300 \times 300 \mathrm{DPI})$ 
Figure 3. MBTPS2 mutation analysis in the Dutch KFSD family. a) Sanger sequencing of exon 11 in the MBTPS2 gene identified a c.1523A>G (p.Asn508Ser) in all affected males of the Dutch KFSD family, not present in WT controls. The variant co-segregates with the disease in this family; affected male (VI-20) c.1523A > G carrier female (VI-27) c.1523AG and unaffected male (VII-6) c.1523G. b) RNA analysis in fibroblasts in the Dutch KFSD family. cDNA sequencing in fibroblasts confirmed the presence of the c.1523A>G variant in an affected male. Carrier females (VI-19, VII11, VI-27, and VII-10) showed variability in the expression of the mutated and the wild type allele. $90 \times 80 \mathrm{~mm}(300 \times 300 \mathrm{DPI})$ 
Table 2. X-inactivation patterns in the Dutch KFSD family.

\begin{tabular}{|l|c|c|l|l|}
\hline Pedigree/sex $(\mathbf{m} / \mathbf{f})$ & DNA $* \mathbf{L}$ & RNA *F & Phenotype & Xi pattern \\
\hline V-20/m & G & G & full & \\
\hline VII-10/f & AG & AG & mild-moderate & $50 \%-50 \%$ \\
\hline VII-11/f & AG & A & none & $100 \%-0 \%$ \\
\hline VI-19/f & AG & G & moderate & $100 \%-0 \%$ \\
\hline VI-27/f & AG & $a^{*} G$ & mild & $100 \%-0 \%$ \\
\hline
\end{tabular}

Levels of X-inactivation in carrier females were compared to the differences in RNA expression in fibroblasts. $a^{*}=$ less expression of the wild type allele compared to other carrier females. The clinical phenotype of carrier females matched with differences in $\mathrm{X}$ inactivation. 
A
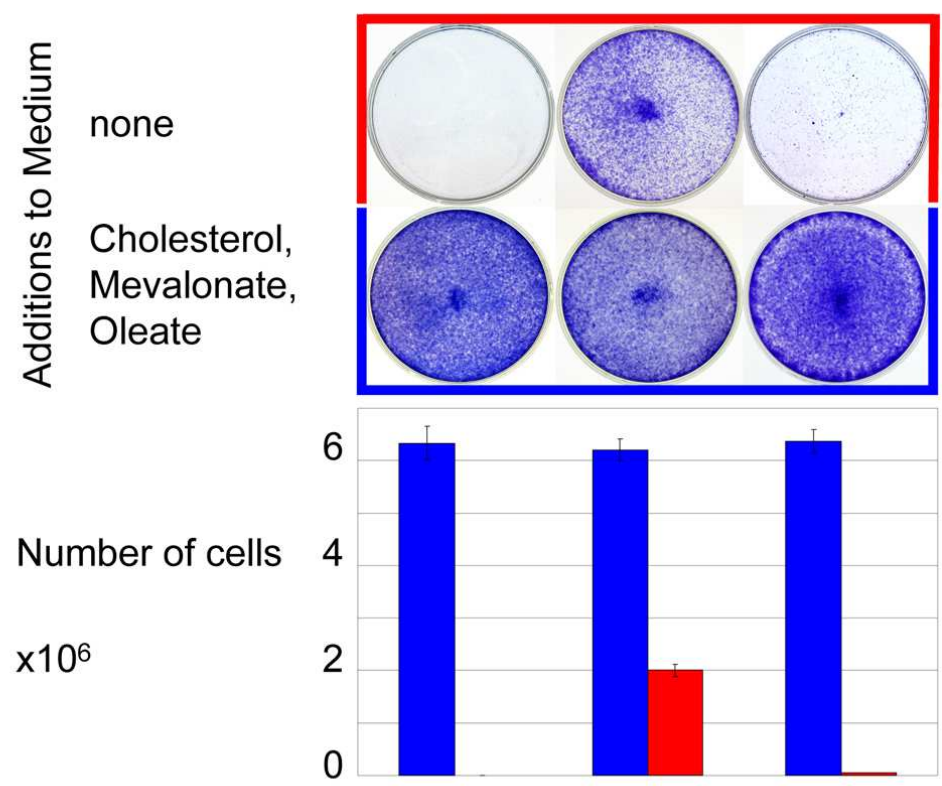

B

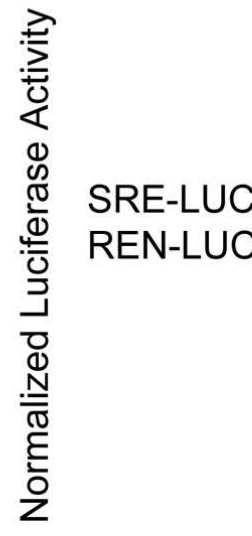

Figure 4. Complementation assay and luciferase reporter assay. Functional studies of the c. $1523 \mathrm{~A}>\mathrm{G}$ (p.Asn508Ser) variant using an in vitro assay testing sterol responsiveness. A. Complementation assay: Growth of stably transfected CHO-K1-M19 cells (lacking hamster MBTPS2) was measured in cholesterol rich medium (blue) and cholesterol deficient medium (red). The proportion of cells capable of growth is documented as framed photographs of the cultures and, graphically in bars by counts of growing stably transfected cells. Colours indicate absence (red) or presence (blue) of sterols. B. Luciferase reporter assay: luciferase activity functions as an indirect measure of the ability of MBTPS2 mutants to restore sterol-regulated transcriptional activity in transfected CHO-K1-M19 cells. Cells transfected with the c.1523A>G (p.Asn508Ser) variant are less able to restore sterol-regulated transcription compared to wild type when transferred from a cholesterol rich (blue bars) to a cholesterol deficient medium (red bars). $85 \times 131 \mathrm{~mm}(300 \times 300 \mathrm{DPI})$ 


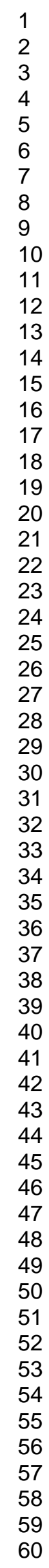




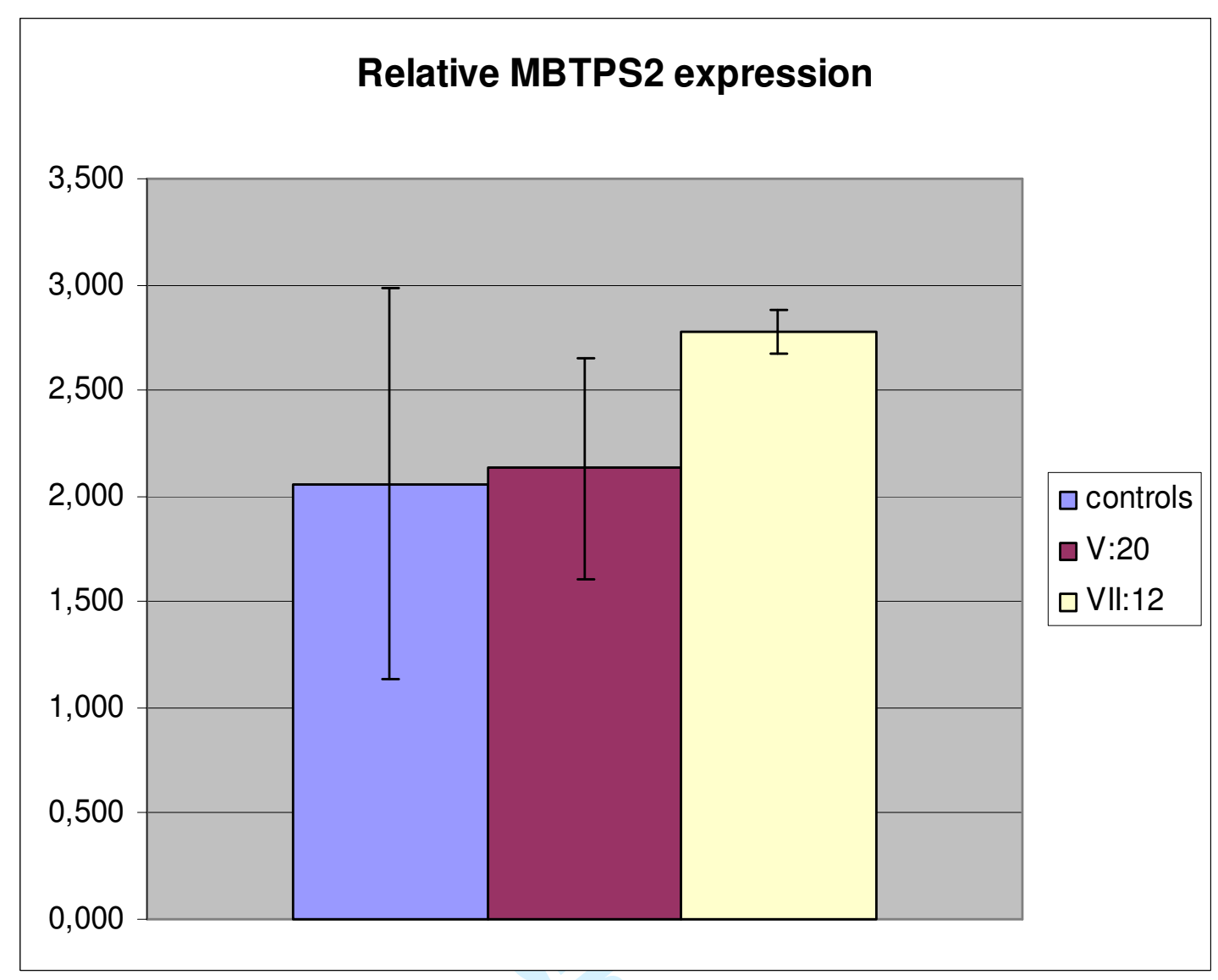

Figure S1: MBTPS2 levels in KFSD males compared to control males 


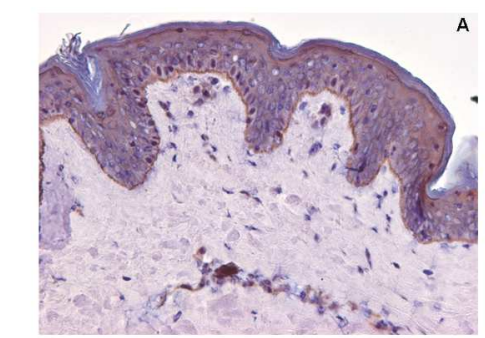

KFSD affected male VII:12

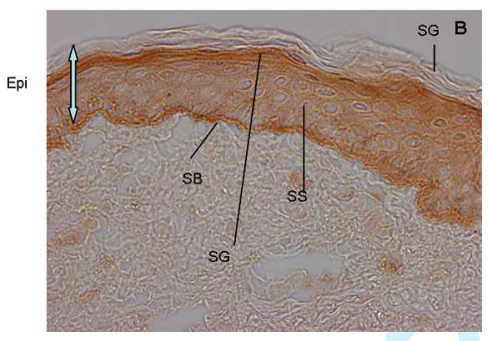

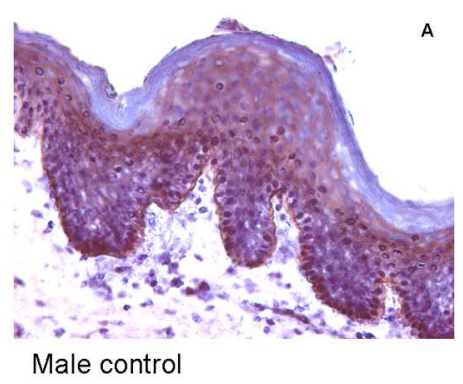

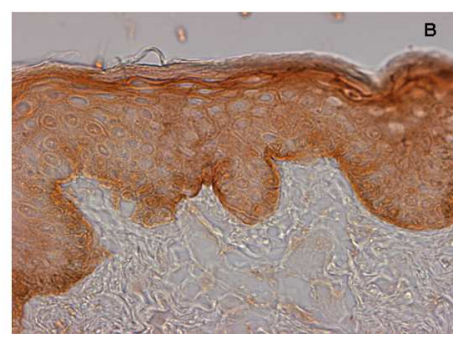

Figure S2: Skin biopsies stained with aMBTPS2 (brown) with (A) and without Hematoxylin (B). 40x and 20x magnification.

Epi=epidermis, $\mathrm{SC}=$ stratum corneum, $\mathrm{SG}=$ stratum granulosum, $\mathrm{SS}=$ stratum spinulosum, $\mathrm{SB}=$ stratum basale.

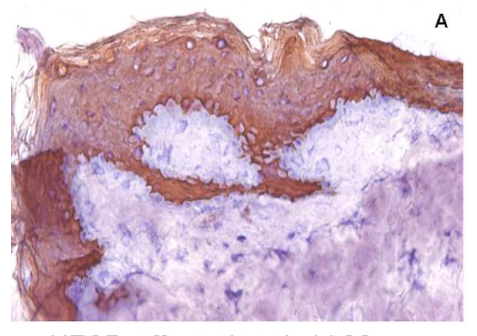

KFSD affected male $\mathrm{V}: 20$

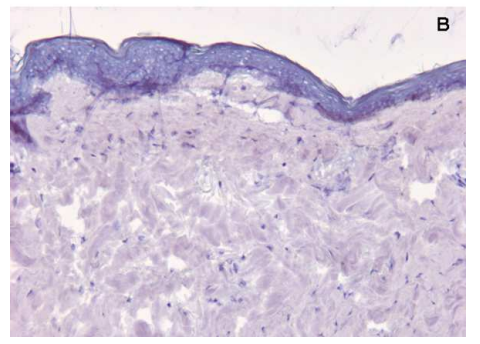

Figure S3: Skin biopsy stained with $\alpha$ Keratin-10 (A) and only counterstaining with Hematoxylin (B). 20x and 10x magnification. Keratin-10 is expressed in the epidermis, except the stratum basale. 
Table S1. Variants detected in the Dutch KFSD family using High Resolution Melting curve Analysis

\begin{tabular}{|l|l|l|}
\hline Gene & Variant & SNP \\
\hline FLJ14503 & NM_152780.2:c.545A $>\mathrm{G}$ & $r s 34519770$ \\
\hline MAP3K15 & NM_001001671.2:c.1533+19G $>\mathrm{G}$ & $r s 56058646$ \\
\hline MBTPS2 & NM_015884.2:c.1523A $>\mathrm{G}$ & - \\
\hline ZNF645 & NM_152577.2:c.498C $>\mathrm{A}$ & rs5951426 \\
\hline
\end{tabular}

All sequence information is based on GenBank reference sequences.

Nucleotide numbering follows HGVS recommendations and is based on a coding DNA reference sequence with nucleotide 1 corresponding to the A of the ATG translation initiation codon (www.hgvs.org/mutnomen).

Table S2. Haplotype comparison around MBTPS2.

\begin{tabular}{|l|l|l|l|l|}
\hline SNP & $\begin{array}{l}\text { UK III-4 } \\
\text { genotype }\end{array}$ & $\begin{array}{l}\text { USA IV-I } \\
\text { genotype }\end{array}$ & $\begin{array}{l}\text { Dutch VII-12 } \\
\text { genotype }\end{array}$ & $\begin{array}{l}\text { Allele frequency } \\
\text { HAPMAP-CEU }\end{array}$ \\
\hline$r s 5951636:[T]$ & $\mathrm{T}$ & $\mathrm{T}$ & $\mathrm{T}$ & 0.750 \\
\hline$r s 16981675:[T]$ & $\mathrm{T}$ & $\mathrm{T}$ & $\mathrm{T}$ & 1.00 \\
\hline$r s 5951640:[C]$ & $\mathrm{C}$ & $\mathrm{C}$ & $\mathrm{C}$ & 0.983 \\
\hline$r s 4446856:[T]$ & $\mathrm{T}$ & $\mathrm{T}$ & $\mathrm{T}$ & 0.992 \\
\hline$r s 6653655:[C]$ & $\mathrm{C}$ & $\mathrm{C}$ & $\mathrm{C}$ & 1.00 \\
\hline
\end{tabular}

Genotype analysis around the c.1523A $>\mathrm{G}$ variant in MBTPS2 of affected KFSD males from three families (UK, USA, Dutch) showed a common haplotype between SNP rs5951636 and rs6653655 with a maximum region of overlap of $50.1 \mathrm{~Kb}$. Allele frequencies of SNPs in this interval indicate a close relationship of these families is not plausible. Polymorphism nomenclature follows dbSNP identifiers and HGVS recommendations (www.hgvs.org/mutnomen) with [..] indicating the major allele. 

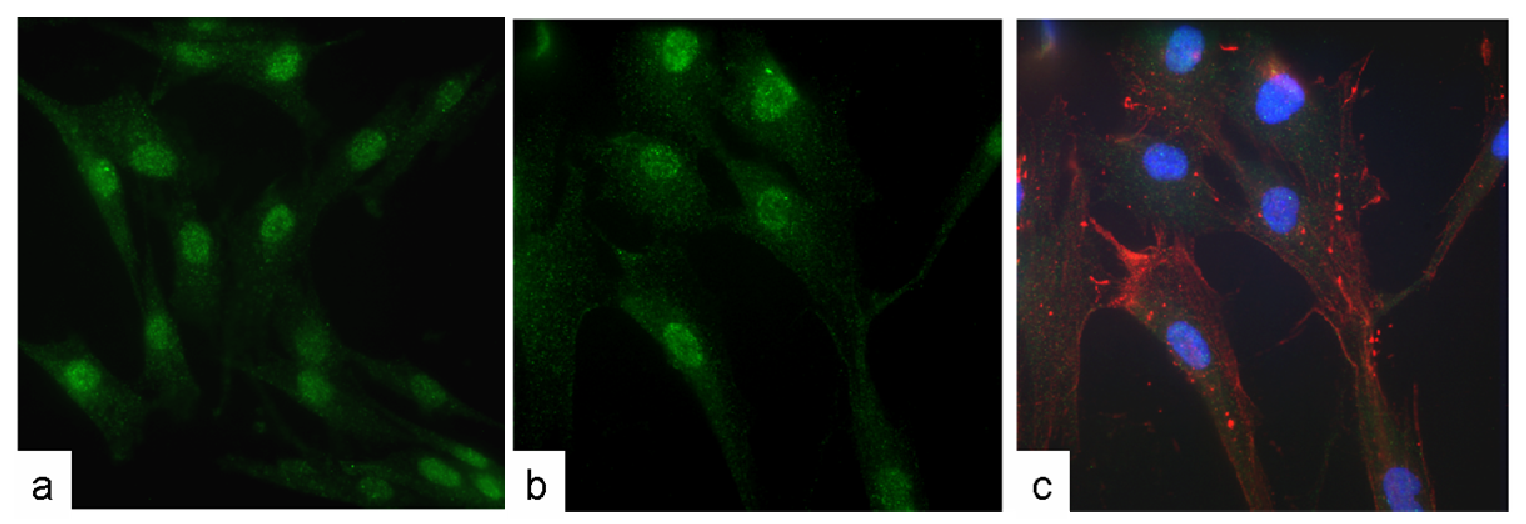

Figure S4: Cellular localisation of MBTPS2 in fibroblasts. There is no difference between a control male (a) and a male KFSD patient VII-12 (b). MBTPS2 (green fluorescence) is found both in the cytoplasm and nucleus. Nuclei are stained in blue with DAPI. Red is a control staining of $\beta$-actin. 